\title{
NON-OPERATIVE MANAGEMENT OF BENIGN COLORECTAL ANASTOMOTIC STENOSIS İN PATIENTS UNDERGOİNG ELECTIVE SURGERY FOR NON-METASTATIC PRIMARY RECTAL CANCER
}

\author{
Ümit Mercan ${ }^{1}$, Ogün Erşen ${ }^{1}$, Cemil Yüksel ${ }^{1}$, Ömer Yalkın ${ }^{2}$, Serkan Akbulut ${ }^{1}$, Ekrem Ünal $^{1}$, Salim Demirci $^{1}$ \\ ${ }^{1}$ Ankara University General Surgery, Surgical Oncology, Mamak, Ankara, Turkey. \\ ${ }^{2}$ Bursa City Hospital General Surgery, Bursa, Turkey.
}

\section{ABSTRACT}

Introduction: Benign anastomosis stenosis may develop in postoperative or long term period due to many reasons such as anastomosis leakage and anastomosis ischemia after colorectal surgery. In this study, we aimed to present our clinical experience in the treatment of benign anastomosis strictures in patients undergoing elective surgery for nonmetastatic primary rectal cancer. Material and Methods: One hundred fifty-six (156) patients who underwent resection and colorectal anastomosis between January 2013 and January 2018 were included in the study: 22 patients developed benign anastomotic stenosis has been determined and etiological factors and treatment modalities applied has been compared retrospectively. Results: In 22 patients, 9 patients were treated with digital or balloon dilatation, at least 2 sessions and up to 5 sessions. Four patients were treated with dilatation followed by stenting. The remaining 9 patients were taken to surgical treatment. Among whole patients with stenosis, it has been determined that 15 of them had neoadjuvant therapy history, 5 had anastomosis leakage and in 16 of them 28 mm circular stapler have been used. Discussion and Conclusion: Neoadjuvant treatment history, the presence of anastomosis leakage and the usage of $28 \mathrm{~mm}$ circular stapler have been detected to be the most important etiological factors in development of benign anastomotic stenosis. Endoscopic treatments should be tried primarily to treat benign anastomotic stenosis. High success rates can be achieved with endoscopic methods and patient quality of life can be improved. With this approach, the need for surgery will be reduced and possible postoperative complications can be prevented.

Keywords: Endoscopy, Rectal Neoplasms, Stenosis

\section{Corresponding Author:}

Ogün Erşen, MD.

Address: Ankara University, Faculty of Medicine, Cebeci Research Hospital, Department of General Surgery, Surgical Oncology Clinic, Mamak, Ankara, Turkey.

E-mail: ogunersen@ hotmail.com

Phone number: +90 5367494399

Copyright (C) 2012- 2020 Dr Ogün Erşen. This is an open access article published under Creative Commons Attribution -Non Commercial- No Derives 4.0 International Public License (CC BY-NC-ND). This license allows others to download the articles and share them with others as long as they credit you, but they can't change them in any way or use them commercially.

doi: $10.46327 / m s r j g .1 .000000000000 x x x$

$* * * * *$ Available on line in June 30, 2020. doi url: https://doi.org/10.46327/msrjg.1.0000000000001xxx

\section{INTRODUCTION}

Rectum cancer surgery continues to be a challenge for surgeons with dissections performed in a restricted area in the narrow bone pelvis and anastomosis technique applied to the lower levels. Factors such as ischemia or tension that may occur in the colon segment that will be anastomosed after resection threaten colorectal anastomosis safety
$(1,2)$. Circular stapler devices, which were used in the 1970s to facilitate colorectal anastomosis and developed over time, have became standard since it is easy and reproducible to perform anastomosis in a shorter time compared to conventional anastomosis methods (3). However, anastomotic ischemia, bleeding and the resulting anastomotic leaks still remain an important problem for colorectal surgeons. 
Stenosis arising from factors such as ischemia, hematoma, anastomotic leak and radiotherapy that affect the anastomotic line in the postoperative early or late period after colorectal anastomoses are considered as benign anastomosis stricture $(4,5)$. Colorectal benign anastomosis stricture is also described as the presence of obstructive symptoms and the inability of passing the rigid proctoscope through the anastomotic line (6). While benign stenoses are seen on average 5\% after colorectal anastomoses, it is reported that they reach $20 \%$ after stapler anastomoses with the effect of the above factors $(5,7)$. While a small portion of these stenoses require surgical treatment, most of them can be treated with endoscopic balloon dilation, stenting, cautious incision of the stricture, use of spark plugtype dilators or sometimes only a simple manual rectal dilatation. These procedures are classified as advanced endoscopic procedures such as endoscopic balloon dilatation, endoscopic sphincterotomy, endoscopic biliary tract stentings, endoscopic polypectomy, endoscopic gastrostomy and must be performed by specialist endoscopists (8). Complication rates, which are $1 \%$ in standard colonoscopy procedures and $5-10 \%$ in advanced endoscopic procedures, vary according to the experience of the endoscopist performing the procedure in such procedures (9). The success and effectiveness of endoscopic treatment have been shown in many studies $(10,11)$. In cases where balloon or spark plug dilation is unsuccessful, the option of treatment with a metallic stent has also been described in studies $(12,13)$. In this study, we aimed to present our clinical experience in nonoperative management of benign colorectal anastomosis strictures in patients operated under elective conditions due to non-metastatic primary rectal cancer.

\section{MATERIAL AND METHODS}

156 patients who underwent resection and colorectal anastomosis at Ankara University Surgical Oncology Clinic between January 2013 and January 2018 were included in the study. The demographic information, clinicopathological data, colonoscopy reports, patient follow-up notes of the patients were retrospectively scanned through the hospital database. Patients urgently operated for bleeding or obstruction, applied coloanal / intersphincteric anastomosis, with recurrent stenosis in the anastomosis line, undergoing primarily surgical treatment due to stenosis, whose data were not available and who were not followed-up after discharge were excluded from the study.

The patients were diagnosed as a result of routine clinical examination and biopsies taken by rectoscopy or colonoscopy. Tumors were divided into three as upper rectum, middle rectum and lower rectum according to colonoscopy results. The upper rectum was observed in 54 patients, the middle rectum in 41 patients, and the lower rectum tumor in 59 patients. A total of 68 patients, preoperative cT3 and cT4 stages, were operated after neoadjuvant therapy, 4 of them had full response, 38 of them had partial response, while 26 of them did not.

In our clinic, all colorectal anastomoses were performed using 31 or $28 \mathrm{~mm}$ circular staples. 31 mm circular stapler in 118 patients and $28 \mathrm{~mm}$ in 38 patients were used for colorectal anastomoses. A diverting ostomy was performed to every patient who had received neoadjuvant therapy, had an organ invasion and had applied anastomosis close to the dentate line. While loop ileostomy was performed to 106 of the patients, loop colostomy was performed to 21 , while ostomy was not performed to 29 of the patients.

In the postoperative follow-up, patients who had tolerated oral intake, had fecal discharge, and had not required inpatient medical treatment were discharged by calling to the outpatient clinic control. Pathological stages of the patients were determined according to the 7th edition of TNM classification of malignant tumors (14). Routine digital rectal examination and rectoscopy were performed to the patients with adjuvant therapy and ostomy before the ostomy was closed. Ostomies of patients without stenosis were closed. All patients who described obstructive symptoms after the ostomy closure or those who did not have and ostomy but described obstructive symptoms in postoperative period were evaluated again with routine rectal digital examination and rectoscopy. Gradual treatment was planned for all patients with stenosis. Depending on the level, maximum of 5 sessions of digital or balloon dilation were performed first. In distal stenosis treatment was started with digital dilatation and in proximal stenosis balloon dilatation were performed initially. When treatment is unsuccessful after digital or baloon dilatation, metallic stent was applied to patients who were found appropriate by the surgeon's assessment (refractory stenosis to the dilation, long segment stenosis, patients who could not be dilated due to technical reasons). Patients with endoscopic treatment failure were treated surgically. 


\section{RESULTS}

Ninety seven of the patients $(62.2 \%)$ included in the study were male and the average age was found to be $62.15 \pm 7.24$. In 98 patients, surgery was started with laparoscopic surgery, while 29 patients were converted for technical reasons, organ invasion and surgical margin safety. It was observed that the majority of patients who were converted were patients who received neoadjuan therapy and had organ invasion.

When the pathology results of the patients were examined, it was seen that there were 14 and 33 patients in the T1 and T2 stages, and 64 and 45 patients in the $\mathrm{T} 3$ and $\mathrm{T} 4$ stages, respectively. There were 73 nod-negative patients, 42 patients were N1, 46 patients were reported as N2. Distal surgical margin length was found to be $2.16 \pm 1.24 \mathrm{~cm}$ on average. While there was no patient with distal surgical margin positivity, radial surgical margin was reported as positive in 7 patients. Adjuvant therapy was applied to 109 patients. The mean postoperative hospitalization time was $8.56 \pm 3.52$ days.

Anastomosis leakage was observed in 11 patients and 4 of them were reoperated. While 3 of the reoperated patients had no ostomy, 1 had loop ileostomy. 9 of the patients who developed leakage consisted of patients who received neoadjuvant therapy. 7 patients were treated non-operatively. Epidemiological and clinicopathological features of the patients included in the study are given in Table I.

Anastomosis stenosis developed in 22 patients in the whole study population. Diversion ostomy was present in 20 (90\%) of patients with stenosis. Two of the patients without ostomy re-applied with obstructive symptoms and the application period was 4.2 months and 5.6 months, respectively. In these two patients, the anastomosis line was expanded and treated with digital dilation and 2 sessions of balloon dilation. In patients with ostomy, $12(54.5 \%)$ had rectal bleeding, $5(22 \%)$ had pain / distension while $10(45 \%)$ were asymptomatic (Table II). These 10 patients were diagnosed with anastomosis stenosis by control digital examination or rectoscopy during the application due to ostomy closure. The mean admission period of these patients was $3.46 \pm 1.24$ months.

Nine patients were treated with digital dilation or balloon dilatation, at least 2 sessions, and most 5 sessions. Four patients were treated with dilatation followed by stenting. The remaining 9 patients were taken to surgical treatment. Among 22 patients with stenosis, 15 of them had neoadjuvant therapy, $5 \mathrm{had}$ anastomosis leakage and in 16 of them $28 \mathrm{~mm}$ circular stapler have been used. The procedures that lead patients to complete treatment are listed in Table III.

Oozing-style bleeding developed after balloon dilation in two patients. While one patient recovered with conservative follow-up, the other patient was placed with a hemostatic sponge. One patient was restented due to stent dislocation. No complications developed in surgically treated patients.

Table I: Epidemiological and clinicopathological features of the patients included in the study.

\begin{tabular}{|c|c|}
\hline \multicolumn{2}{|l|}{ Gender $(\mathbf{n} / \%)$} \\
\hline Male & $97 / 62.2$ \\
\hline Female & $59 / 37.8$ \\
\hline Age $($ mean \pm SE) & $62,15 \pm 7,24$ \\
\hline \multicolumn{2}{|l|}{ Tumor Localisation } \\
\hline Upper rectum / rectosigmoid junction & 54 \\
\hline Middle rectum & 41 \\
\hline Lower rectu & 59 \\
\hline Neoadjuvant Treatment & 68 \\
\hline Adjuvant Treatment & 109 \\
\hline \multicolumn{2}{|l|}{ Surgical Prosedure } \\
\hline Laparoscopic & 98 \\
\hline Conventional & 29 \\
\hline \multicolumn{2}{|l|}{ Surgical Technique } \\
\hline Anterior resection & 23 \\
\hline Low anterior resection & 101 \\
\hline Ultra-low anterior resection & 32 \\
\hline \multicolumn{2}{|l|}{ Stapler Size } \\
\hline $31 \mathrm{~mm}$ & 118 \\
\hline $28 \mathrm{~mm}$ & 38 \\
\hline \multicolumn{2}{|l|}{ Diversiyon ostomy } \\
\hline Ileostomy & 106 \\
\hline Colostomy & 21 \\
\hline \multicolumn{2}{|l|}{ T Stage* } \\
\hline $\mathrm{T} 1$ & 14 \\
\hline $\mathrm{T} 2$ & 33 \\
\hline $\mathrm{T} 3$ & 64 \\
\hline $\mathrm{T} 4$ & 45 \\
\hline \multicolumn{2}{|l|}{ N Stage* } \\
\hline No & 73 \\
\hline N1 & 42 \\
\hline $\mathrm{N} 2$ & 46 \\
\hline
\end{tabular}


Table II: Symptomatology in patients with benign anastomotic stenosis.

\begin{tabular}{cc}
\hline Symptoms & $\mathbf{n} / \%$ \\
\hline Rectal bleeding & $12 / 54.5$ \\
Abdominal pain/Distension & $5 / 22$ \\
Asymptomatic & $10 / 45$ \\
\hline
\end{tabular}

Table III: Features and therapeutic procedures of patients with benign anastomosis stenosis.

\begin{tabular}{ccccc}
\hline \multicolumn{1}{c}{$(\mathrm{n} / \%)$} & Digital dilatation & Baloon dilatation & Metallic Stent & Surgical Treatment \\
\hline Radiotherapy & $3 / 100$ & $4 / / 66$ & $2 / 50$ & $6 / 66$ \\
Anastomotic Leak & $0 / 0$ & $0 / 0$ & $1 / 25$ & $4 / 44$ \\
$28 \mathrm{~mm}$ stapler & $3 / 100$ & $6 / 100$ & $3 / 75$ & $4 / 44$ \\
$31 \mathrm{~mm}$ stapler & $0 / 0$ & $0 / 0$ & $1 / 25$ & $5 / 55$ \\
Total & 3 & 6 & 4 & 9 \\
\hline
\end{tabular}

\section{DISCUSSION}

Benign colorectal stenoses are recognized as the anastomosis lumen being too narrow to allow the passage of the scope and the occurrence of complaints such as constipation-diarrhea attacks, abdominal pain and bleeding (15). In such benign stenosis after colorectal surgery, many causes including ischemia, radiotherapy and bleeding from the anastomosis line play a role in etiology, and unfortunately no method has been identified in the literature that can completely prevent anastomotic stenosis. Anastomotic strictures, which are the result of the excessive proliferation of the fibroblasts and cross-linking of collagen fibers, represent a challenging complication after colorectal resection $(16,17)$. In particular, circular staplers interlock muscle and serosal tissues between both mucosa in the anastomotic line and this causes scar formation resulting in anastomotic stenosis (18). Also an another reason for the development of stenosis in the long term is that sirculer stapler forms an anastomotic ring structure that cannot expand. While these stenoses can be observed in the first 3 months postoperatively, there are publications stating that they appeared late in the 10 years later $(19,20)$. In our study, patients with ostomy and stenosis were diagnosed for an average of 3.46 months before the closure of ostomy, while 2 patients without ostomy and stenosis were diagnosed in a slightly longer period of 4,2 and 5,6 months, respectively. Circular stapler diameter is an another risk factor for the development of stenosis. Due to the diameter of the colon lumen, stenosis develops more frequently due to the smaller anastomotic ring that occurs in cases with low caliber circular staples. In our study, patients who were treated with dilatation or stent and who underwent surgery due to no response were observed to be in the group with $28 \mathrm{~mm}$ circular stapler.While some of the anastomotic strictures are detected during the examinations to explain obstructive symptoms, some of them are diagnosed coincidentally at colonoscopy. A group of patients who remain asymptomatic in up to $40 \%$ in benign anastomosis stenosis has been reported (21). Especially, diverting ostomies performing for anastomosis safety after colorectal anastomoses prevent the formation of obstructive symptoms in patients (7). In our study, it was observed that there was a $45 \%$ asymptomatic patient group and in the majority of these patients, diagnosis of the anastomotic stenosis was made with rectoscopy performed for control before the closure of the ostomy after adjuvant treatment. Considering this situation, the control with rectoscopy for the condition of anastomosis of all patients with or without symptoms before ostomy closure should be adopted as a standard clinical approach.

While surgical treatment was applied in all anastomotic stenoses unresponsive to treatment in the past, endoscopic treatments have been replaced by surgery as a more minimally invasive method (21). Tumor recurrence should be excluded by biopsies taken from the anastomosis line in all cases before anastomotic stenosis is thought to be treated with the endoscopic methods. Endoscopic treatments include Savary-Giliard polyvinyl spark plugs (22) or balloon dilatation (23), endoscopic stricturoplasty or stricturotomies (24) and metallic stents in treatmentresistant cases (25). In addition, there are combined methods in which two or three small radial electroincisions are performed under endoscopic 
examination followed by 15-20 minute balloon dilatation is applied (26).

In balloon dilatation, the force acts radially, thus the dilatation force acts along the entire stricture line. For this reason, the rupture seen in dilatations with rigid spark plugs is more rare in this method (27). While a single session may be sufficient in 30-40\% of patients, an average of 2 to 4 sessions of dilatation is generally required (28). In our study, the majority of patients were treated with digital and balloon dilatation. In addition, while there was no patient that could be treated in a single session, success was achieved with at least 2 and up to 5 sessions of dilatation. If the diameter of the stenosis is less than $5 \mathrm{~mm}$ and the length is more than $1 \mathrm{~cm}$, it decreases the success of endoscopic treatment and is associated with the increased perforation rates after the intervention. Surgical treatment should be considered primarily in these patients. In our study, it was observed that 9 patients treated with the surgical method had a long segment stenosis without response to dilatation or almost complete stenosis that did not allow stenting.

Today, two balloon types are used in endoscopic dilatation. The balloon, called through-the-scope (TTS), is passed through the accessory channel of the colonoscope and is placed in the stricture area under the view of the scope and fluoroscopy. In the over-the-wire (OTW) balloon type, after the guidewire is passed through the anastomosis, the balloon is advanced over it and the dilatation process is performed by inflating the baloon in an appropriate position under the view of the scope. OTW balloon is preferred in our clinical practice because our results are better and this method is easy to apply and cost effective. In our study, balloon dilatation was performed under analgesia with petidine hydrochloride and sedation with propofol, by using a $35 \mathrm{~mm}$ diameter, $10 \mathrm{~cm}$ long OTW achalasia balloon that passed through anastomotic line in the aid of $14 \mathrm{fr}$. guide wire. In each session, the dilatation balloon was inflated 2 times in a 3minute period using saline and 15 per square inch (PSI) pressure was applied on the first day and 20 PSI pressure was applied on the second day. In cases requiring more dilation, it should be kept in mind that complication rates related to the procedure also increase. In cases that have been successfully treated with dilatation, recurrence may develop due to the underlying etiological factor in the short or long term period. In a study conducted by Acar et al, it was observed that stenosis recurred in $7(11 \%)$ of 59 patients undergoing endoscopic intervention (29). In such cases, although there is a chance to be treated with endoscopic methods, surgical treatment should also be considered.

Due to a restricted sample group, the low adaptability of the study results to the general population and the possible selection bias caused by a retrospective publication made from a single center constitute the lack of our study. It is also possible that performing of primary operations by different surgeons may have affected the results. Despite all these limitations, we think that our clinical experience in the nonoperative management of benign anastomosis strictures may be a light on prospective studies.

As a result, benign anastomotic stenosis is seen more frequently after $28 \mathrm{~mm}$ circular stapler usage, improved anastomosis leakage and neoadjuvant treatment and so it should be kept in mind that stenosis may have developed even in asymptomatic patients. Recurrent digital and balloon dilatation or metallic stenting should be tried in the primary treatment of benign anastomosis strictures that may occur after colorectal surgery. High success rates can be achieved with endoscopic methods and patient quality of life can be improved. With this approach, the need for surgery will be reduced and possible postoperative complications can be prevented.

\section{ACKNOWLEDGMENT}

I would like to thank all members of the Turkish Surgical Oncology Association supported writing of this article.

\section{DISCLOSURE STATEMENT}

There is no conflict of interest in writing of this article. No financial support or funding has been received.

\section{REFERENCES}

1. Polese, L., Vecchiato, M., Frigo, A. C., Sarzo, G., Cadrobbi, R., Rizzato, R., ... \& Merigliano, S. (2012). Risk factors for colorectal anastomotic stenoses and their impact on quality of life: what are the lessons to learn?. Colorectal Disease, 14(3), e124-e128.

2. Chung, R. S., Hitch, D. C., \& Armstrong, D. N. (1988). The role of tissue ischemia in the pathogenesis of anastomotic stricture. Surgery, 104(5), 824-829.

3. Mirnezami, R., Soares, A., \& Chand, M. (2019). Enhancing the precision of circular stapled colorectal anastomosis: could powered stapler technology provide the solution?. Techniques in coloproctology, 23(7), 687-689. 
4. Polglase AL, Hughes ES, McDermott FT, Pihl E, Burke FR. A comparison of end-to-end stapler and suture colorectal anastomosis in the dog. Surg Gynecol Obstet 1981;152:792-6.

5. Ridtitid, W., Siripun, A., \& Rerknimitr, R. (2018). Stricture at colorectal anastomosis: to dilate or to incise. Endoscopy international open, 6(03), E340E341.

6. Bannura, G. C., Cumsille, M. A. G., Barrera, A. E., Contreras, J. P., Melo, C. L., \& Soto, D. C. (2004). Predictive factors of stenosis after stapled colorectal anastomosis: prospective analysis of 179 consecutive patients. World journal of surgery, 28(9), 921-925.

7. Yılmaz S, Bal A, Özkeçeci Z, Celep R, Özsoy M , Erşen O, Okur N, Arıkan Y . Laparoskopik low anterior rezeksiyon sonrası oluşan anastomoz darlığında balon dilatasyon uygulaması: İki olgu sunumu. Marmara Medical Journal. 2015; 28(1): 4945.

8. Akııı, M., Erşen, O., Çelık, G., \& Çılekar, M. (2019). Experiences With Percutaneous Endoscopic Gastrostomy In A General Surgery Clinic. Medical Journal of Suleyman Demirel University, 26 (3).

9. Özsoy, M., Celep, B., Ersen, O., Özkececi, T., Bal, A., Yılmaz, S., \& Arıkan, Y. (2014). Our results of lower gastrointestinal endoscopy: evaluation of 700 patients. Turkish Journal of Surgery/Ulusal cerrahi dergisi, 30(2), 71.

10. Araujo SE, Furtado Costa A (2008) Efficacy and safety of endoscopic balloon dilation of benign anastomotic strictures after oncologic anterior rectal resection. Report on 24 cases. Surg Laparosc Endosc Percutaneous Tech 18:565-568

11. Belvedere B, Frattaroli S, Crabone A, Viceconte G (2012) Anastomotic strictures in colorectal surgery: treatment with endoscopic balloon dilation. G Chir $33: 243-245$

12. Lamazza, A., Fiori, E., Sterpetti, A. V., Schillaci, A., Scoglio, D., \& Lezoche, E. (2014). Self-expandable metal stents in the treatment of benign anastomotic stricture after rectal resection for cancer. Colorectal Disease, 16 (4), O150-O153.

13. Reddy, R., Patel, U., Tarnasky, P., \& Kedia, P. (2018). Lumen-apposing stent placement for management of a short benign colonic anastomotic stricture. VideoGIE, 3 (3), 99.

14. Wittekind C. 2010 TNM system: on the 7th edition of TNM classification of malignant tumors. Pathologe 2010; 31: 331-332.

15. Di Giorgio P, De Luca L, G, et al. Endoscopic dilation of benign colorectal anastomotic stricture after low anterior resection: A prospective comparison study of two balloon types. Gastrointest Endosc 2004;60:34750.

16. Kwon J. H., Han K. H., Kim M. H., et al. Two cases of electrocautery incision therapy using an insulatedtip knife for treatment of symptomatic benign shortsegment colonic stenosis following colonic resection. The Korean Journal of
Gastroenterology. 2014;64(3):164-167.

doi: 10.4166/kjg.2014.64.3.164.

17. Bravi I., Ravizza D., Fiori G., et al. Endoscopic electrocautery dilation of benign anastomotic colonic strictures: a single-center experience. Surgical Endoscopy. 2016;30(1):229-232.

10.1007/s00464-015-4191-0.

18. Huang C., Xu X., Zhuang B., vd. Özofajektomi sonrası servikal delta şekilli anastomoz ve dairesel zımbalanmış anastomozun karşılaştırılması. Dünya Cerrahi Onkoloji Dergisi .2017; 15 (1): s. 31. doi: 10.1186 / s12957-017-1097-4.

19. Luchtefeld MA, Milsom JW, Senagore A, Surell JA, Mazier WP. Colorectal anastomotic stenosis. Results of a survey of the ASCRS membership. Dis Colon Rectum 1989;32:733-6. doi:10.1007/BF02562119

20. Weinstock LB, Schatz BA. Endoscopic alternatives in the management of the anastomosis following resection of colonic neoplasm. Gastrointest Endosc 1994;40:558-61

21. Yaman İ, Derici H. Kolon benign anastomoz darlığında endoskopik balon dilatasyon. Kolon Rektum Hast Derg 2010;20:134-38.

22. Werre A, Mulder C, van Heteren C, Bilgen ES. Dilation of benign strictures following low anterior resection using Savary-Gilliard bougies. Endoscopy 2000;32:385-8. doi:10.1055/s-2000-8999

23. Solt J, Hertelendi A, Szilágyi K. Balloon catheter dilatation of lower gastrointestinal tract stenoses: long-term results. Orv Hetil 2002;143:1835-40

24. Dieruf LM, Prakash C. Endoscopic incision of a postoperative colonic stricture. Gastrointest Endosc 2001;53:522-4. doi:10.1067/mge.2001.112369

25. Delaunay K, Barthelemy C, Dumas O, Balique JG, Audigier JC. Endoskopic therapy of benign colonic postoperative strictures: report on 27 cases. Gastroenterol Clin Biol 2003;27:610-3.

26. Hoffmann JC, Heller F, Faiss S, et al. Through the endoscope balloon dilation of ileocolonic strictures: prognostic factors, complications, and effectiveness. Int J Colorectal Dis 2008;23:689-96. doi:10.1007/s00384-008-0461-9

27. Di Giorgio P, De Luca L, G, et al. Endoscopic dilation of benign colorectal anastomotic stricture after low anterior resection: A prospective comparison study of two balloon types. Gastrointest Endosc 2004;60:34750.

28. Di Giorgio P, De Luca L, G, et al. Endoscopic dilation of benign colorectal anastomotic stricture after low anterior resection: A prospective comparison study of two balloon types. Gastrointest Endosc 2004;60:34750

29. Acar, T., Aslan, F., Acar, N., Kamer, E., Ünsal, B., \& Haciyanl,, M. (2019). Role of endoscopic interventions and electroincision in benign anastomotic strictures following colorectal surgery. The Turkish Journal of Gastroenterology, 30(8), 673. 